\title{
ACUMULACIÓN DE CAPITAL: FICCIÓN Y REALIDAD
}

\author{
Shimshon Bichler* \\ Jonathan Nitzan**
}

\section{LA TESIS DEL DESAJUSTE}

¿Qué quieren decir los economistas cuando hablan de "acumulación de capital"? Sorprendentemente, la respuesta a esta pregunta es todo menos clara, y parece mucho menos clara en épocas de crisis. Consideremos la "crisis financiera" de finales de la década pasada. E1 mismo término ya indica la supuesta naturaleza y las causas de la crisis, que la mayoría de los observadores creen que se originó en el sector financiero y fue ampliada por la financiarización.

Pero cuando los teóricos hablan de una crisis financiera no hablan de ella de manera aislada. No se refieren a las finanzas en sí mismas, sino en relación con lo que llaman cantidad de capital real. La crisis reciente -argumentan- ocurrió no debido a las finanzas como tales sino a un desajuste entre capital financiero y capital real. El mundo de las finanzas -se lamentan- se desvió y distorsionó el mundo real de la acumulación.

Según el guión convencional, este desajuste suele aparecer como una "burbuja", una enfermedad recurrente que infla las finanzas con respecto a la realidad. La burbuja, como el cáncer, se expande sigilo-

* Profesor de economía política en universidades de Israel

** Profesor de economía política en York University, Canadá, [nitzan@yorku. ca]. Todas sus publicaciones están disponibles gratuitamente en The Bichler \& Nitzan Archives (http://bnarchives.net). E1 trabajo para este escrito fue apoyado en parte por el SSHRC. Este artículo es una versión editada de la presentación de Jonathan Nitzan en marzo de 2015 ante la Asociación de Estudiantes de Ciencias Económicas (AESE) de la Universidad de Quebec. Tomado de RealWorld Economics Review 72, 30 de septiembre de 2015, pp. 47-68. Traducción de Alberto Supelano. Se publica con las autorizaciones correspondientes. Fecha de recepción: 5 de octubre de 2015, fecha de aceptación: 29 de octubre de 2015. Sugerencia de citación: Bichler, S. y J. Nitzan "Acumulación de capital: ficción y realidad”, Revista de Economia Institucional 17, 33, 2015, pp. 45-71. DOI: http:// dx.doi.org/10.18601/01245996.v17n33.03 
samente. Es muy difícil detectarla, y mientras está creciendo, nadie salvo algunos catastrofistas- parece capaz de verla. Solo después de que el mercado estalla y el polvo se asienta, repentinamente todos saben que siempre fue una burbuja. Ahora bien, las burbujas, como otras desviaciones, distorsiones y desajustes, surgen del pecado. Comienzan con un "público" muy ambicioso y "autoridades de política" demasiado laxas, continúan con una "exuberancia irracional" que conjura la riqueza ficticia surgida de la nada y terminan con una crisis financiera, seguida de una recesión, con pérdidas enormes y alto desempleo; un castigo merecido para quienes creyeron que podían engañar a Milton Friedman para que les diera un almuerzo gratis.

Esta "tesis del desajuste"-la noción de una realidad distorsionada por las finanzas- es ampliamente aceptada. En 2009, The Economist de Londres acusó a sus lectores de confundir "los activos financieros con activos reales", y señaló que esa confusión era la causa básica de la crisis (gráfica 1). La revista explicó que los activos reales, o riqueza, consisten en "bienes y productos que deseamos consumir" o en "cosas que nos dan la capacidad para producir más de lo que deseamos consumir". Los activos financieros, en cambio, no son riqueza; son simplemente "reclamaciones de riqueza real". Confundir la inflación de estos últimos con la expansión de los primeros es la receta más segura para el desastre.

Gráfica 1

La dicotomía clásica: lo real y lo financiero

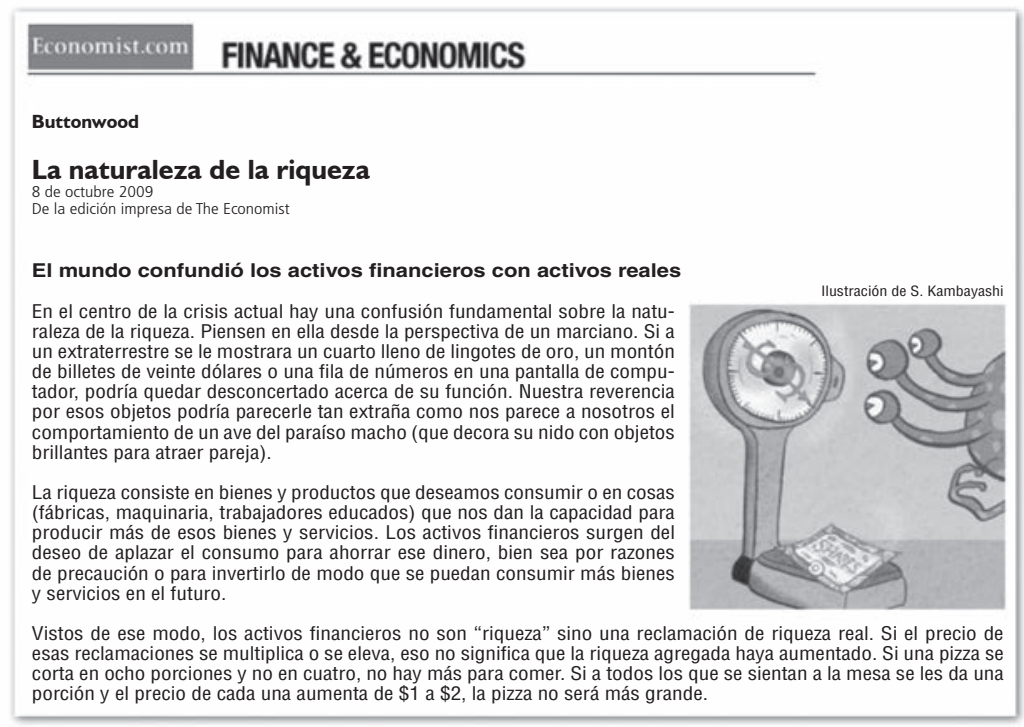

Revista de Economía Institucional, vol. i7, N. ${ }^{\circ} 33$, segundo semestre/20i5, Pp. 45-7i 
La división entre riqueza real y reclamaciones financieras de riqueza real es una premisa fundamental de la economía política. Esta premisa es aceptada no solo por teóricos, analistas y autoridades de política liberales sino también por marxistas de diversas corrientes. Y como veremos, es una premisa construida sobre bases muy endebles ${ }^{1}$.

Cuando los liberales y los marxistas dicen que hay un desajuste entre capital financiero y capital real, hacen explícita o implícitamente tres afirmaciones relacionadas: 1) que son entidades independientes, 2) que estas entidades deberían corresponderse mutuamente y 3) que, en el mundo real, a menudo no se corresponden.

En lo que sigue explicamos por qué no son válidas estas afirmaciones. Hablando sin tapujos, ni los liberales ni los marxistas saben cómo comparar el capital real y el financiero, y la principal razón es simple: primero, no saben cómo determinar la magnitud del capital real. La solución común y provisional es calcular indirectamente esta magnitud, usando el precio en dinero de los bienes de capital; aunque esto no soluciona el problema porque los bienes de capital pueden tener muchos precios y no hay manera de saber cuál de ellos es el "verdadero". Por último y no menos importante, aun si hacemos la vista gorda y admitimos estas imposibilidades lógicas y estos trucos empíricos, el resultado es aún muy perturbador. Pues la acumulación financiera no solo se desvía de la acumulación real y la distorsiona (o así se nos dice), sino que también sigue una trayectoria opuesta. Durante más de dos siglos, los economistas de izquierda y derecha han argumentado que los capitalistas -y por tanto el capitalismoprosperan con base en la "inversión real" y el crecimiento del "capital real”. Pero, como veremos, en la realidad jla mejor época para los capitalistas es cuando su "acumulación real" decae!

\section{LA DUALIDAD REAL-NOMINAL}

La dualidad entre sujeto y objeto, idea y cosa, nomos y physis ha preocupado a los filósofos desde la antigüedad. También ha dado un apalancamiento ideal a las religiones organizadas y a otros dogmas especializados en salvarnos de la alienación. Y, más recientemente, ha llegado a ser el fundamento básico de la economía moderna.

Siguiendo la "dicotomía clásica" propuesta por el filósofo británico David Hume, los economistas dividen su economía en dos mundos paralelos: el real y el nominal. El más importante de esos dos dominios

\footnotetext{
${ }^{1}$ No todos los economistas políticos se consideran liberales o marxistas, pero aun los no alineados tienden a aceptar la división entre capital real y activos financieros.
} 
es, de lejos, la economía real. Este es el dominio de la escasez, la arena donde la demanda y la oferta asignan recursos limitados entre necesidades ilimitadas. Donde tienen lugar la producción y el consumo, donde se derraman sudor y lágrimas y se cumplen los deseos, donde los factores de producción se combinan con la tecnología, donde los capitalistas invierten por la ganancia y los trabajadores laboran por un salario. Donde el conflicto se une a la cooperación, las fuerzas del mercado anónimas se comprometen con la mano visible del poder, se lleva a cabo la explotación y se acumula el capital real. Es la razón de ser de la reproducción social, el lugar de la acción, el medio y el fin de la economía. En suma, es la cosa real.

La economía nominal solo refleja esta realidad. A diferencia de la economía real, con sus esfuerzos productivos, sus bienes tangibles y sus servicios útiles, la esfera nominal es totalmente simbólica. Sus diversas entidades - el dinero fiduciario y los precios monetarios, el crédito y la deuda, las acciones y los títulos- se denominan en dólares y centavos (o en otras unidades monetarias). Se cuentan en parte en monedas acuñadas y billetes impresos, pero en su mayor parte en bits y bytes electrónicos. Este es un universo paralelo, un mundo de espejos y de ecos, una imagen desnuda de la cosa real.

Esta dualidad real-nominal atraviesa toda la economía, incluido el capital. Para los economistas, el capital viene en dos variedades: capital real (riqueza) y capital financiero (capitalización). El capital real está hecho de "bienes de capital". Abarca los medios de producción, incluidos la planta y el equipo, la infraestructura, la obra en marcha y, según muchos, el conocimiento. El capital financiero, o capitalización, es una reclamación simbólica sobre el capital real. Su cantidad mide el valor presente de las ganancias que se espera reditúen los bienes de capital subyacentes.

Los marxistas y los neoclásicos aceptan la bifurcación real-nominal de la economía. También aceptan que hay dos tipos de capital: real y financiero. Y también creen (en el caso marxista) y aceptan (en el caso neoclásico) que usualmente hay un desajuste entre ellos. La principal diferencia entre ambas escuelas es la dirección del desajuste: los marxistas empiezan con un desajuste que según argumentan debe ajustarse, mientras que los neoclásicos empiezan con un ajuste que, a regañadientes admiten, a menudo se desintegra en un desajuste. Examinemos un poco más de cerca esta diferencia, empezando por la visión marxista ${ }^{2}$.

2 Una distinción sutil: la mayoría de los marxistas acepta la dualidad realnominal y la diferencia entre capital real y financiero (o ficticio). Pero solo los marxistas clásicos anclan su aceptación en la teoría del valor trabajo de Marx. Los 


\section{LA VISIÓN MARXISTA}

Marx escribió a mediados del siglo XIX, casi medio siglo antes de que otros empezaran a teorizar en serio la capitalización y un siglo antes de que se volviera el ritual central del capitalismo moderno. Pero tenía suficiente clarividencia para entender la importancia de este proceso e intentó determinar qué significaba para su teoría del valor trabajo.

Comenzó estipulando dos tipos de capital: real y ficticio. La clave era el capital real: los medios de producción y el trabajo en marcha contabilizado en tiempo de trabajo. Este era el capital "real". El capital ficticio -o capitalización- era la magnitud del ingreso futuro esperado descontada a su valor presente. A este capital, contabilizado en dólares y centavos, lo consideró ficticio por tres razones básicas: 1) a menudo no hay un "principal" que se pueda reclamar (como en el caso de la deuda del gobierno, donde el acreedor no posee capital real sino una mera reclamación sobre los ingresos del gobierno, 2) la capitalización se basa en las variantes expectativas de ingreso que pueden o no materializarse, y 3 ) aun si se logra el ingreso esperado, su valor capitalizado varía con la tasa de descuento.

La existencia de dos tipos de capital le planteó un dilema. Teóricamente, el capital real y el ficticio son criaturas diferentes de magnitudes totalmente distintas. Pero la realidad capitalista se denomina en precios, lo que significa que, en la práctica, el capital real y el ficticio están profundamente entrelazados. Esta última fusión -dice Marx- provoca grandes distorsiones, en particular durante un auge, a menudo hasta el punto de hacer "ininteligible" el proceso de acumulación en su totalidad:

\footnotetext{
Así se pierde hasta el último vestigio de toda conexión con el proceso real de auto expansión del capital y se refuerza la concepción de capital como algo que se expande automáticamente a sí mismo [...] La acumulación de la riqueza por esta clase [los grandes capitalistas adinerados] puede ir en una dirección muy diferente de la acumulación real [...] Además, aquí todo parece al revés, pues en este mundo hecho de papel no aparecen precios reales ni su base real, solo lingotes, monedas, billetes, letras de cambio y títulos. Esta inversión es clara particularmente en los centros, en los que se concentra todo el negocio de dinero del país, como Londres, donde el proceso en su totalidad se vuelve incomprensible (Marx, 1894, 549, 561, 576, cursivas añadidas).
}

Los seguidores de Marx resolvieron este problema suponiendo que la teoría del valor trabajo prevalece en el largo plazo (con precios proporcionales al valor trabajo) y, por tanto, que en algún momento debe haber una crisis "financiera" que vuelva a alinear el precio del capital ficticio con el valor trabajo del capital real:

neo marxistas tienden a eludir del todo la teoría del valor, y con ello eliminan la base teórica en la que podrían apoyar sus nociones de capital real y financiero. 
Para que el sistema de precios funcione, las fuerzas financieras deben llevar a que los capitales ficticios se muevan en dirección paralela a los cambios en los valores de reproducción [...] Al perder toda relación con el sistema de valores subyacente se generan tensiones en la esfera de la producción, hasta que se requiere una crisis para que el sistema vuelva al equilibrio, y los precios reflejen el costo real de producción. La ficción del valor ficticio no se puede mantener indefinidamente. En algún momento desconocido del futuro los precios tendrán que retornar a la conformidad con los valores (Perelman, 1990, 83).

\section{LA CASA DE LOS ESPEJOS DE FISHER}

En el lado neoclásico, la dualidad del capital real y financiero fue expuesta hace un siglo por el economista estadounidense Irving Fisher. Este fue el comienzo de un proceso al que los comentaristas contemporáneos llaman financiarización, cuya estructura lógica Fisher fue uno de los primeros teóricos en sistematizar. El cuadro 1 y la cita siguiente esbozan su marco.

Cuadro 1

La casa de los espejos de Fisher

\begin{tabular}{llcc}
\hline & Capital actual & & Ingreso futuro \\
\hline Cantidades (reales) & Capital riqueza & $\mathbf{O} \rightarrow$ & Servicios del ingreso \\
& & & $\downarrow$ (2) \\
Valores (financieros) & Valor del capital & $\leftarrow \mathbf{3}$ & Valor del ingreso \\
\hline
\end{tabular}

La afirmación de que "el capital produce ingreso" solo es verdadera en el sentido físico; no es verdadera en el sentido de valor. Es decir, el capital-valor no produce ingreso-valor. Por el contrario, el valor-ingreso produce valor-capital [...] Cuando el capital y el ingreso se miden en valor, su conexión causal es contraria a la que existe cuando se miden en cantidades. El huerto produce las manzanas; pero el valor de las manzanas produce el valor del huerto [...] Vemos, entonces, que la riqueza-capital presente produce servicios-ingreso futuros, pero el valor-ingreso futuro produce valor-capital presente (Fisher, 1907, 13-14, cursivas del original).

En esta cita Fisher describe tres vínculos básicos: 1) la cantidad de bienes de capital, que los economistas consideran riqueza, genera servicios de ingreso futuros; 2) los servicios de ingreso futuros generan los valores del ingreso futuros correspondientes, y 3) los valores del ingreso futuros, capitalizados en el aquí y el ahora, dan al capital su valor financiero.

Y así se resuelve la antigua alienación entre la cosa y la idea. E1 capital real en el lado de los activos del balance se hace igual al capital financiero en el lado de los pasivos. Las máquinas, las estructuras, los inventarios y el conocimiento, tomados como magnitud agregada, son equivalentes a la suma del capital y la deuda de la corporación. Lo nominal refleja lo real. El nomos y la physis son finalmente una y la misma cosa. 
Es cierto que este solo es el estado ideal, el equilibrio último que una economía libre y racional debe alcanzar. Aunque tristemente, como los neoclásicos reconocen con gran dolor, aún no estamos allí. En la práctica, la economía de aquí y ahora es alterada continuamente por choques, imperfecciones y distorsiones que, lamentablemente, desvían las finanzas de su valor real y adecuado, y el equilibrio sigue siendo una meta distante.

\section{LA CANTIDAD DE RIQUEZA}

En síntesis, los marxistas y los neoclásicos abordan la dualidad realnominal desde direcciones opuestas. En el caso marxista, la dualidad empieza como un desajuste que eventualmente es forzado a ajustarse, mientras que en el caso neoclásico empieza como un ajuste que se distorsiona en un desajuste.

Pero en ambos casos -y este es el punto clave- el punto de referencia es el capital real o capital actual. Esta es la norma, la cantidad subyacente a la que las finanzas supuestamente se ajustan o desajustan. En algún momento, bien sea al comienzo o al final del proceso, el valor capitalizado de las finanzas debe ser igual a la cantidad de riqueza sobre la cual este constituye una reclamación. En otras palabras, todo el ejercicio se basa en la cantidad material de bienes de capital. El único problema es que nadie sabe cuál es esa cantidad ni cómo medirla.

\section{ÚTILES Y TTASN}

En la década de 1960 hubo una controversia muy importante en economía, que enfrentó a profesores heterodoxos de la Universidad de Cambridge en Inglaterra con algunos profesores ortodoxos del MIT en Cambridge, Massachusetts. Los economistas del Reino Unido afirmaban que la economía ortodoxa se basaba en una falacia: trataba el capital como si tuviese una cantidad definida mientras que, de hecho, no se podía demostrar que esa cantidad existía. Demostraron que el capital rara vez se puede medir en sus unidades materiales “naturales". Los de Estados Unidos eventualmente estuvieron de acuerdo. Admitieron a regañadientes que el capital real es una mera "parábola". Como el Dios siempre elusivo, se puede hablar de él, pero, en general no se lo puede cuantificar.

La Controversia de Cambridge, como se conoció después, fue sepultada y olvidada. Los libros de texto no la mencionan, la mayoría de los profesores no han oído hablar de ella y desde luego no la 
enseñan, y los estudiantes, no informados, la ignoran felizmente ${ }^{3}$. La razón del secreto no es difícil de entender: aceptar que el capital real no tiene una cantidad definida es poner fin a la economía moderna tal como la conocemos. Para evitar este sino, los científicos sombríos han tomado el camino anticientífico de lavar los trapos sucios en casa. Han ignorado sus propias conclusiones, han borrado gradualmente el debate de sus currículos y programas de estudio y fortificado las murallas que rodean a su religión académica para alejar a los infieles.

Pero el problema continúa y, dadas sus consecuencias devastadoras, vale la pena considerarlo, así solo sea brevemente. La razón básica para que el capital real no se pueda medir es la agregación. Visto como una entidad económica productiva, el capital consiste en objetos cualitativamente diferentes: los tractores son diferentes de los camiones, los barcos son diferentes de los aviones y las fábricas de automóviles son diferentes de las plataformas petroleras. Esta heterogeneidad explica por qué los economistas heterodoxos de Cambridge afirmaron que el capital no tiene una "unidad natural": simplemente no hay manera alguna de comparar y sumar sus componentes, y esa incapacidad hace difícil decidir "cuán grande" o "cuán pequeño" es ${ }^{4}$.

La solución común en tales casos es la reducción, es decir, retroceder un paso para idear una cantidad fundamental común a todas las entidades en cuestión. Quizá el primero en utilizar ese método fue el filósofo griego Tales, cuando afirmó que todas las cosas del mundo están hechas de agua. Los físicos usan ese mismo principio cuando argumentan que toda cantidad del universo se puede expresar en términos de masa, distancia, tiempo, carga eléctrica o calor (así velocidad $=$ distancia/tiempo, aceleración $=$ tasa de cambio de la velocidad, fuerza $=$ masa $\mathrm{x}$ aceleración, etc.).

Los economistas imitan este reduccionismo con sus propias cantidades fundamentales. Para los neoclásicos, esa cantidad es el “útil”, una medida que denota el placer hedonista generado por las mercancías 5 .

${ }^{3}$ En la presentación de este escrito en la Universidad de Quebec, Nitzan preguntó a los asistentes cuántos habían oído hablar de la Controversia de Cambridge. De unas 50 personas, en su mayoría estudiantes de economía, solo una levantó la mano. Había oído hablar de ella en una clase de sociología.

${ }^{4} \mathrm{Al}$ parecer desconocido para los polemistas de Cambridge, el economista político estadounidense Thorstein Veblen expuso este argumento a comienzos del siglo XX.

${ }^{5}$ Los neoclásicos duros podrían objetar esta descripción diciendo que los útiles son únicos para el individuo y que por ello es imposible sumarlos entre individuos. Pero puesto que seguir esta objeción al pie de la letra haría imposible la comparación y la agregación -y con ello la economía práctica-, la mayoría de los economistas neoclásicos tiende a ignorarla. Para pasar por alto su lógica individualista liberal suponen que todos los individuos son iguales y, por tanto, perfectamente comparables, y que sus utilidades se pueden agregar después de todo. 
Como cualquier otra mercancía, cada bien de capital tiene su propia capacidad para generar útiles, y si sumamos la capacidad individual para generar útiles de los diferentes bienes de capital obtenemos su medida agregada como capital real. Por ejemplo, si una fábrica Toyota puede producir 1 millón de útiles y una plataforma petrolera de BP 2 millones de útiles, su capital real combinado es de 3 millones de útiles.

Los marxistas clásicos hacen la misma cosa con el tiempo de trabajo. Cada mercancía -dicen- puede ser medida por el tiempo de trabajo abstracto socialmente necesario (TTASN) que se toma para producirla, y sumando esos tiempos podemos calcular la cantidad real agregada del capital en cuestión. Si una fábrica Toyota toma 100 millones de horas de trabajo abstracto socialmente necesario y una plataforma petrolera de BP 200 millones de horas, su cantidad total es de 300 millones de horas.

Hasta aquí todo va bien, pero surge entonces un pequeño aunque arduo problema: a diferencia de los físicos, los economistas nunca han logrado medir realmente sus cantidades fundamentales. Hasta donde sabemos, ningún liberal ha observado jamás un útil, y ningún marxista ha identificado jamás una unidad de TTASN. Tal como son, estas "cantidades reales" son, de hecho, totalmente ficticias.

Pero los economistas no se han dado por vencidos. En vez de medir útiles y TTASN directamente, van en reversa. Dios nos es revelado a través de sus milagros, y eso mismo ocurre -argumentan los economistas- con las cantidades fundamentales de la economía: se nos revelan a través de sus precios. Para un neoclásico, una relación de precios de 1:2 entre una fábrica Toyota y una plataforma petrolera de BP significa que la primera entidad tiene la mitad de la cantidad de útiles que la segunda, mientras que para un marxista clásico esta misma relación de precios es una prueba de que la cantidad de TTASN de la primera entidad es la mitad de la segunda.

Esta solución inversa es el pan de cada día de toda economía práctica. Es un procedimiento común que todos los economistas usan y pocos cuestionan, y mucho menos critican. Es utilizado por todo el mundo, desde estadísticos oficiales y economistas del gobierno hasta analistas de Wall Street y estrategas corporativos. Y como nuestro lector puede ahora sospechar, no funciona; al menos no de la manera que se supone.

\section{EQUILIBRANDO EL CAPITAL SOCIAL}

Para ver por qué la solución de reserva no funciona, consideremos el cuadro 2 y la gráfica 2, que presentan la misma información, numérica 
y gráficamente. El cuadro y la gráfica corresponden a una compañía hipotética, Energy User-Producer Inc., que posee dos activos: fábricas de automóviles que usan energía y plataformas petroleras que la producen. Para simplificar el ejemplo suponemos que solo hay un tipo de fábricas de automóviles y que todas las plataformas petroleras son idénticas. Para saber "cuánto" capital de cada tipo hay solo necesitamos contar. E1 cuadro 2 muestra el número de cada uno de esos "activos reales": la columna 1 , el número de fábricas de automóviles a medida que cambia con el tiempo; y la columna 2, el número correspondiente de plataformas petroleras. En la parte inferior de la gráfica 2 se muestran esos mismos números para las dos series. Las columnas 3 y 4 del cuadro muestran, para cada año, el precio unitario de cada tipo de activo, contabilizado en millones de dólares.

Ahora bien, puesto que las fábricas de automóviles y las plataformas petroleras son entidades diferentes no se pueden agregar en sus propias unidades "naturales". Y puesto que no conocemos su contenido en útiles ni en TTASN, tampoco podemos sumar esos números. Pero podemos seguir la receta económica de "preferencias reveladas" para ir hacia atrás, de los precios a los útiles o al TTASN.

Consideremos la inversión neoclásica ${ }^{6}$. Para conjeturar útiles a partir de precios, todo lo que necesitamos hacer es identificar un año de equilibrio perfectamente competitivo (EPC). Así, en aras del argumento, supongamos que ese año fue 1970. Este es un supuesto conveniente, porque se dice que en EPC los compradores y vendedores intercambian mercancías a precios proporcionales a sus preferencias denominadas en útiles (marginales) ${ }^{7}$. En nuestro caso, los números en negrillas y sombreados del cuadro 2 muestran que, en 1970, una fábrica de automóviles costó $\$ 200$ millones y una plataforma petrolera $\$ 100$ millones (ambos son números hipotéticos). Y como se supone que son precios EPC, su relación presuntamente revela que la capacidad de una fábrica de automóviles para generar útiles es el doble de la de una plataforma petrolera.

Recordemos que para simplificar también suponemos que todas las fábricas de automóviles y todas las plataformas petroleras son iguales, y que no cambian con el tiempo. Este supuesto, junto con nuestro conocimiento de que 1970 fue un año de EPC, nos permite

\footnotetext{
${ }^{6}$ La inversión marxista sería igual, solo que en vez de útiles generaría TTASN.

${ }^{7}$ Los economistas neoclásicos insisten en distinguir entre utilidad promedio y marginal. Pero puesto que los útiles son por siempre invisibles, y dado que, en interés de la agregación, los individuos neoclásicos se reducen a robots idénticos con preferencias homotéticas de todos modos, no es necesario que esta distinción nos distraiga.
} 
calcular fácilmente la cantidad total de capital que posee Energy UserProducer. Para cada año basta multiplicar el número de fábricas de automóviles por 200 y el número de plataformas petroleras por 100, y luego sumar los dos productos. Este cálculo nos daría entonces la capacidad de la compañía para generar útiles, año tras año, como se muestra en la columna 5 .

Pero aquí hay una trampa odiosa.

Observen que nuestros cálculos suponen que el EPC ocurrió en 1970; pero, ¿qué sucede si este supuesto es erróneo? ¿Qué sucede si el EPC no ocurrió en 1970 sino en 1974, cuando el precio del petróleo era tres veces más alto y la inflación estaba fuera de control?

De acuerdo con el cuadro 2, en 1974 el precio de las fábricas de automóviles era de $\$ 300$ millones cada una -un 50\% mayor que en 1970 - y el de las plataformas petroleras era un 200\% mayor, $\$ 300$ millones. Si tomamos estos precios como nuestros precios EPC, y por ello revelan la capacidad verdadera de los activos subyacentes para generar útiles, la cantidad de capital sería muy diferente a la del primer escenario. A diferencia de antes, la proporción de precios no es ahora $2: 1$, sino $1: 1$, y esa diferencia cambia todo. Los nuevos resultados se muestran en la columna 6.

Esa pregunta se puede hacer de nuevo: ¿qué sucede si el EPC no ocurrió en 1974, sino en 1979, cuando la inflación se aceleró aún más y el precio de las plataformas petroleras se disparó? Según el cuadro 2 , la proporción de precios es ahora 1:2, y ese cambio, documentado en la columna 7 , hace que las cantidades de capital sean diferentes a las de ambos escenarios anteriores.

Para comparar mejor la evolución de la cantidad de capital en nuestros tres escenarios de EPC es conveniente normalizar las columnas 5-7, como hacemos en las columnas 8-10. Para cada una de las columnas 5-7, dividimos la cantidad de capital por su valor en 1970 y multiplicamos el resultado por 100. Este cálculo recalibra las tres series llevándolas a un solo común denominador, de modo que sus valores respectivos en 1970 son iguales a 100. Nótese que debido a que cada observación de esta transformación se divide y se multiplica por los mismos números, los cambios temporales relativos de las columnas 8-10 son idénticos a los de las columnas 5-7, respectivamente (aunque no en números absolutos).

La parte superior de la gráfica 2 muestra las tres cantidades de capital normalizadas para el año EPC correspondiente (columnas 8-10). Como se puede ver, las trayectorias de las series difieren notablemente entre sí: si el EPC ocurrió en 1970, la cantidad de capital disminuye en 
Cuadro 2

Las muchas “cantidades” de Energy User-Producer Inc.

\begin{tabular}{|c|c|c|c|c|c|c|c|c|c|c|}
\hline \multirow[b]{2}{*}{ Año } & \multicolumn{2}{|c|}{ Número } & \multicolumn{2}{|c|}{$\begin{array}{c}\text { Precio } \\
\text { (\$ millones) }\end{array}$} & \multicolumn{3}{|c|}{$\begin{array}{c}\text { “Cantidad” de capi- } \\
\text { tal (útiles) por año de } \\
\text { equilibrio }\end{array}$} & \multicolumn{3}{|c|}{$\begin{array}{c}\text { “Cantidad" normalizada } \\
\text { de capital (útiles) } \\
\text { por año de equilibrio }\end{array}$} \\
\hline & $\begin{array}{c}\text { (1) } \\
\text { Fábricas } \\
\text { de autos }\end{array}$ & $\begin{array}{c}\text { (2) } \\
\text { Plataformas }\end{array}$ & $\begin{array}{c}\text { (3) } \\
\text { Fábricas } \\
\text { de autos }\end{array}$ & $\begin{array}{c}\text { (4) } \\
\text { Plataformas }\end{array}$ & $\begin{array}{l}(5) \\
\text { Eq. en } \\
1970\end{array}$ & $\begin{array}{l}\text { (6) } \\
\text { Eq. en } \\
1974\end{array}$ & $\begin{array}{l}\text { (7) } \\
\text { Eq. en } \\
1979\end{array}$ & $\begin{array}{l}\text { (8) } \\
\text { Eq. en } \\
1970\end{array}$ & $\begin{array}{l}\text { (9) } \\
\text { Eq. en } \\
1974\end{array}$ & $\begin{array}{l}\text { (10) } \\
\text { Eq. en } \\
1979\end{array}$ \\
\hline 1970 & 33 & 20 & 200 & 100 & 8.600 & 15.900 & 29.200 & 100,0 & 100,0 & 100,0 \\
\hline 1971 & 32 & 20 & 220 & 120 & 8.400 & 15.600 & 28.800 & 97,7 & 98,1 & 98,6 \\
\hline 1972 & 31 & 20 & 218 & 220 & 8.200 & 15.300 & 28.400 & 95,3 & 96,2 & 97,3 \\
\hline 1973 & 28 & 20 & 270 & 280 & 7.600 & 14.400 & 27.200 & 88,4 & 90,6 & 93,2 \\
\hline 1974 & 28 & 21 & 300 & 300 & 7.700 & 14.700 & 28.000 & 89,5 & 92,5 & 95,9 \\
\hline 1975 & 28 & 21 & 345 & 400 & 7.700 & 14.700 & 28.000 & 89,5 & 92,5 & 95,9 \\
\hline 1976 & 28 & 21 & 350 & 450 & 7.700 & 14.700 & 28.000 & 89,5 & 92,5 & 95,9 \\
\hline 1977 & 28 & 24 & 410 & 600 & 8.000 & 15.600 & 30.400 & 93,0 & 98,1 & 104,1 \\
\hline 1978 & 28 & 30 & 390 & 700 & 8.600 & 17.400 & 35.200 & 100,0 & 109,4 & 120,5 \\
\hline 1979 & 28 & 31 & 400 & 800 & 8.700 & 17.700 & 36.000 & 101,2 & 111,3 & 123,3 \\
\hline 1980 & 28 & 32 & 415 & 810 & 8.800 & 18.000 & 36.800 & 102,3 & 113,2 & 126,0 \\
\hline 1981 & 28 & 33 & 432 & 820 & 8.900 & 18.300 & 37.600 & 103,5 & 115,1 & 128,8 \\
\hline 1982 & 28 & 33 & 445 & 850 & 8.900 & 18.300 & 37.600 & 103,5 & 115,1 & 128,8 \\
\hline 1983 & 28 & 33 & 450 & 900 & 8.900 & 18.300 & 37.600 & 103,5 & 115,1 & 128,8 \\
\hline 1984 & 28 & 30 & 432 & 850 & 8.600 & 17.400 & 35.200 & 100,0 & 109,4 & 120,5 \\
\hline 1985 & 27 & 30 & 450 & 870 & 8.400 & 17.100 & 34.800 & 97,7 & 107,5 & 119,2 \\
\hline 1986 & 27 & 29 & 460 & 800 & 8.300 & 16.800 & 34.000 & 96,5 & 105,7 & 116,4 \\
\hline 1987 & 27 & 29 & 473 & 790 & 8.300 & 16.800 & 34.000 & 96,5 & 105,7 & 116,4 \\
\hline 1988 & 27 & 30 & 470 & 690 & 8.400 & 17.100 & 34.800 & 97,7 & 107,5 & 119,2 \\
\hline 1989 & 27 & 31 & 460 & 650 & 8.500 & 17.400 & 35.600 & 98,8 & 109,4 & 121,9 \\
\hline 1990 & 26 & 32 & 500 & 680 & 8.400 & 17.400 & 36.000 & 97,7 & 109,4 & 123,3 \\
\hline 1991 & 26 & 33 & 502 & 700 & 8.500 & 17.700 & 36.800 & 98,8 & 111,3 & 126,0 \\
\hline 1992 & 25 & 33 & 510 & 720 & 8.300 & 17.400 & 36.400 & 96,5 & 109,4 & 124,7 \\
\hline 1993 & 25 & 33 & 500 & 705 & 8.300 & 17.400 & 36.400 & 96,5 & 109,4 & 124,7 \\
\hline 1994 & 25 & 36 & 480 & 730 & 8.600 & 18.300 & 38.800 & 100,0 & 115,1 & 132,9 \\
\hline 1995 & 24 & 36 & 511 & 780 & 8.400 & 18.000 & 38.400 & 97,7 & 113,2 & 131,5 \\
\hline 1996 & 23 & 36 & 520 & 785 & 8.200 & 17.700 & 38.000 & 95,3 & 111,3 & 130,1 \\
\hline 1997 & 22 & 37 & 510 & 800 & 8.100 & 17.700 & 38.400 & 94,2 & 111,3 & 131,5 \\
\hline 1998 & 17 & 38 & 530 & 750 & 7.200 & 16.500 & 37.200 & 83,7 & 103,8 & 127,4 \\
\hline 1999 & 17 & 40 & 535 & 760 & 7.400 & 17.100 & 38.800 & 86,0 & 107,5 & 132,9 \\
\hline 2000 & 17 & 41 & 540 & 755 & 7.500 & 17.400 & 39.600 & 87,2 & 109,4 & 135,6 \\
\hline 2001 & 17 & 40 & 560 & 730 & 7.400 & 17.100 & 38.800 & 86,0 & 107,5 & 132,9 \\
\hline 2002 & 17 & 42 & 550 & 780 & 7.600 & 17.700 & 40.400 & 88,4 & 111,3 & 138,4 \\
\hline 2003 & 18 & 43 & 530 & 800 & 7.900 & 18.300 & 41.600 & 91,9 & 115,1 & 142,5 \\
\hline 2004 & 18 & 44 & 580 & 850 & 8.000 & 18.600 & 42.400 & 93,0 & 117,0 & 145,2 \\
\hline 2005 & 19 & 45 & 550 & 900 & 8.300 & 19.200 & 43.600 & 96,5 & 120,8 & 149,3 \\
\hline 2006 & 17 & 46 & 590 & 950 & 8.000 & 18.900 & 43.600 & 93,0 & 118,9 & 149,3 \\
\hline 2007 & 15 & 47 & 600 & 1000 & 7.700 & 18.600 & 43.600 & 89,5 & 117,0 & 149,3 \\
\hline 2008 & 14 & 51 & 610 & 800 & 7.900 & 19.500 & 46.400 & 91,9 & 122,6 & 158,9 \\
\hline 2009 & 13 & 52 & 590 & 700 & 7.800 & 19.500 & 46.800 & 90,7 & 122,6 & 160,3 \\
\hline 2010 & 13 & 51 & 580 & 750 & 7.700 & 19.200 & 46.000 & 89,5 & 120,7 & 157,5 \\
\hline 2011 & 14 & 54 & 530 & 700 & 8.200 & 20.400 & 48.800 & 95,3 & 128,3 & 167,1 \\
\hline 2012 & 12 & 52 & 510 & 800 & 7.600 & 19.200 & 46.400 & 88,4 & 120,7 & 158,9 \\
\hline 2013 & 11 & 55 & 520 & 820 & 7.700 & 19.800 & 48.400 & 89,5 & 124,5 & 165,7 \\
\hline 2014 & 12 & 55 & 500 & 800 & 7.900 & 20.100 & 48.800 & 91,9 & 126,4 & 167,1 \\
\hline 2015 & 10 & 57 & 515 & 700 & 7.700 & 20.100 & 49.600 & 89,5 & 126,4 & 169,9 \\
\hline
\end{tabular}

Notas: el número de fábricas de automóviles (columna 1) y de plataformas petroleras (columna 2) es hipotético.

Columna 5 = valor de la columna 3 en 1970 x columna 1 + valor de la columna 4 en 1970 x columna 2.

Columna 6 = valor de la columna 3 en 1974 x columna 1 + valor de la columna 4 en 1974 x columna 2.

Columna 7 = valor de la columna 3 en 1979 x columna 1 + valor de la columna 4 en 1979 x columna 2.

Columna 8 = columna $5 /$ valor de la columna 5 en $1970 * 100$.

Columna 9 = columna $6 /$ valor de la columna 6 en $1970 * 100$

Columna $10=$ columna $7 /$ valor de la columna 7 en $1970 * 100$. 
Gráfica 2

Las muchas “cantidades” de Energy User- Producer Inc.

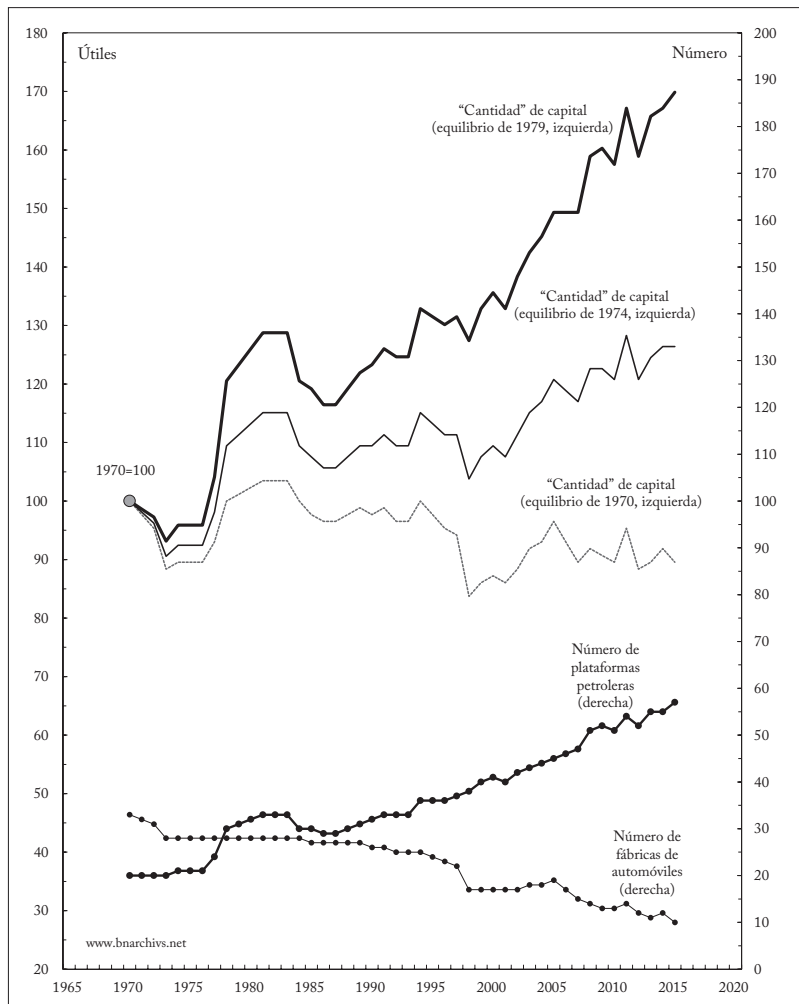

Nota: el número de fábricas de automóviles y de plataformas petroleras es hipotético. La "cantidad" anual de capital (en útiles) se calcula multiplicando el número de fábricas de automóviles y de plataformas petroleras por su precio de equilibrio respectivo; y luego sumando los dos productos. La "cantidad" de capital con un equilibrio en 1970 supone que la "capacidad para generar útiles” de una fábrica de automóviles y de una plataforma petrolera tiene una proporción de 2:1 (basada en los precios respectivos de $\$ 200$ y \$100); la “cantidad" de capital con un equilibrio en 1974 supone que la proporción es 1:1 (basada en los precios respectivos de $\$ 300$ y $\$ 300$ ); y la “cantidad" de capital con un equilibrio en 1979 supone que la proporción es 1:2 (basada en los precios respectivos de $\$ 400$ y $\$ 800$ ). Por propósitos de presentación, las tres series de cantidad de capital se normalizaron con el año $1970=100$.

un 10\% en todo el periodo; si el EPC ocurrió en 1974, la cantidad de capital aumenta en un 20\%; y si el EPC ocurrió en 1979, la cantidad de capital aumenta casi en un 90\%.

\section{DE MODO QUE HAY DESAJUSTE}

Estos son solo tres ejemplos, y como nuestro lector puede ya imaginar, podemos dar muchos otros - de hecho, tantos como deseemos-, basados en un EPC diferente, que generan series cuantitativamente diferentes. El punto esencial aquí es que todas estas series diferentes pertenecen a la misma cantidad de capital, y obviamente solo una de ellas puede ser correcta, si hay alguna; ¿pero cuál es? 
Tristemente, nadie lo sabe.

Hasta donde conocemos, nadie - ni siquiera los ganadores del premio Nobel en ciencias económicas- puede identificar el EPC cuando lo ve (suponiendo que es un estado social significativo, para empezar). $\mathrm{Y}$ en la medida en que el EPC sigue siendo invisible, no hay manera de decidir cuál serie muestra la "verdadera" magnitud del capital.

Problemas similares acosan a los marxistas. Como el TTASN no es directamente observable, y mucho menos medible, los marxistas, igual que los neoclásicos, se ven forzado a ir en reversa. Deducen la magnitud del capital en tiempo de trabajo a partir de los precios de mercado de los bienes de capital (¿EPC?); o, peor aún, simplemente usan las medidas neoclásicas basadas en útiles proporcionadas por las cuentas nacionales ${ }^{8}$.

Y así completamos el círculo. La tesis del desajuste afirma que la cantidad de capital financiero se desvía de la cantidad de capital real y la distorsiona. Pero la cantidad de capital real -la cosa que según las finanzas supuestamente se desajusta y se distorsiona- es de hecho totalmente nominal. Además, puesto que esta cantidad nominal puede ser cualquiera (dependiendo de nuestra elección arbitraria del EPC), los economistas se quedan sin una medida única (en dinero) del capital real, y mucho menos una medida en la que todos puedan estar de acuerdo. Atrapados en la caverna de Platón, intentan ver la realidad a partir de su reflejo en el espejo que fabricaron; para descubrir que este espejo proyecta no una sino un número infinito de imágenes, y que no tienen ni idea de cómo elegir entre ellas. Terminan sin ninguna referencia real a la que ajustarse y por tanto sin nada que se desajuste.

\section{MARCHANDO CON LA MULTITUD DELIRANTE}

En cualquier otra ciencia, esta incapacidad para medir la categoría clave de la teoría sería devastadora (pensemos en la medición de la gravitación de Newton sin masa o distancia). Pero no en la ciencia de la economía ${ }^{9}$.

\footnotetext{
${ }^{8}$ Para más detalles sobre el tratamiento marxista clásico del capital, ver Nitzan y Bichler (2009, caps., 6-8). Aquí basta mencionar que en su investigación empírica muchos marxistas han tirado la toalla metodológica. En vez de recurrir al tiempo de trabajo y al método dialéctico, usan datos "reales" neoclásicos, clasificaciones liberales y econometría basada en equilibrios. Esta rendición total es similar a la de los físicos que retornan a la astrología y de los químicos que retornan a la alquimia. Además, la mayoría de los marxistas rara vez reconoce y mucho menos evalúa las implicaciones de esta rendición, iy el puñado que lo hace a menudo termina defendiéndola!

${ }^{9}$ Una nota para los no iniciados: el término "economics" fue acuñado a finales del siglo XIX por Alfred Marshall, quien pensaba que el término "economía
} 
Aquí, todo marcha sin problemas. Los servicios nacionales de estadísticas ordenan a sus estadísticos que obtengan números "reales" de la cantidad de capital (y de cualquier otra entidad económica). Para cumplir, los estadísticos deben identificar casos de EPC; pero como tampoco tienen ni idea del tema, disimulan. Designan un año arbitrario como su EPC, pasan a través de los aros del cuadro 2 y sacan los números requeridos. Y aunque esos números oficiales son ficticios, los economistas, neoclásicos y heterodoxos, no parecen preocuparse. Los usan, habitualmente sin reflexionar, como si fuesen la cosa real.

No perturbemos el desfile y por el momento sigamos marchando con la multitud delirante. En aras de la discusión supongamos, junto con el economista promedio, que en cualquier momento el valor en dólares de los bienes de capital -o riqueza, como Irving Fisher los llamó- es proporcional a su cantidad real, y usemos esta (pseudo) medida real como nuestra referencia básica.

Con este supuesto, ahora podemos hacer una prueba pragmática: podemos tomar la magnitud financiera de un capital (capitalización de mercado) y compararla con su referencia "real" (fabricada: el precio monetario agregado de los bienes de capital subyacentes). Según las escrituras neoclásicas de Fisher resumidas en el cuadro 1 -y suponiendo que estamos usando el verdadero punto de EPC-, las dos cantidades deben ser iguales. Si difieren, la realidad ha debido ser "distorsionada".

\section{MICROSOFT VERSUS GENERAL MOTORS}

Lo que resta del artículo extrae sus ejemplos empíricos de Estados Unidos. Este enfoque, dictado en gran medida por la disponibilidad de datos, es por supuesto una limitación. Pero dado que Estados Unidos fue el principal motor del capitalismo durante buena parte del siglo XX y sigue siendo esencial para la acumulación global contemporánea, su experiencia aún nos puede decir muchas cosas.

La gráfica 3 ilustra un caso simple de "realidad distorsionada por las finanzas". La gráfica, que corresponde a 2005, compara los llamados lados real y financiero de dos de las principales firmas de Estados Unidos: Microsoft y General Motors. Vistas desde el lado real, General Motores es un gigante y Microsoft un enano. En 2005, General Motors tenía 335 mil trabajadores $-5,5$ veces más que $\mathrm{Mi}$ crosoft $-\mathrm{y}$ planta y equipos por un valor contable de 78 mil millones de dólares, 33 veces mayor que el de Microsoft.

política” no era suficientemente científico, y que el sufijo la haría sonar mucho más respetable, como matemáticas y física. 
Gráfica 3

General Motors versus Microsoft, 2005

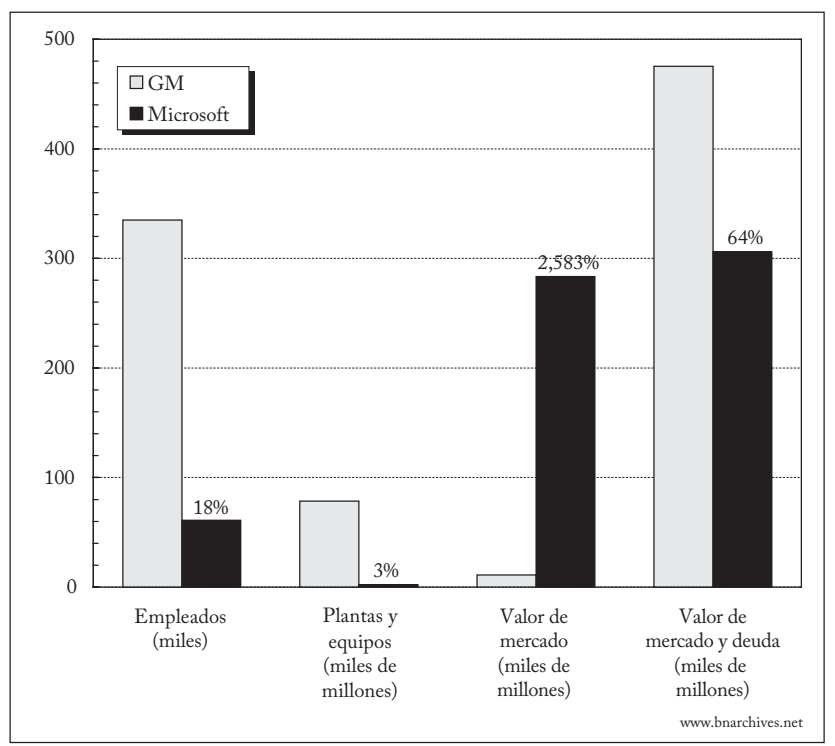

Nota: las cifras en porcentaje indican, para una medida dada, el tamaño de Microsoft con respecto al de General Motors. Fuente: Compustat a través de WRDS (códigos de serie: data29 para empleados, data8 para planta y equipo netos, data24 para el precio, data54 para acciones comunes pendientes y data181 para obligaciones totales).

Pero cuando examinamos las dos compañías a través del lente financiero de la capitalización, el orden jerárquico se invierte: Microsoft se convierte en el gigante y General Motors en el enano. En 2005, Microsoft tenía una capitalización de mercado de casi 26 veces la de General Motors. Incluso si tomamos la suma de la deuda y del valor de mercado, General Motors es aún apenas un 55\% más grande que Microsoft; muy lejos de su relativamente enorme fuerza de trabajo y su vasta "cantidad" de planta y equipo.

Es obvio que aquí debe haber alguna "distorsión”, pues de lo contrario, ¿cómo podría un enano ser un gigante y un gigante un enano?

Sin embargo, la mayoría de los economistas eludirían la pregunta. El problema -dirían- es que la gráfica solo muestra parte de la imagen. Mide el capital real observando la planta y el equipo y el número de empleados, pero esas magnitudes no captan la importancia de la “tecnología”. Esta es una omisión crucial -continuarían- pues como todos sabemos, Microsoft es una compañía de alta tecnología y posee mucha más tecnología que General Motors. Y como el conocimiento técnico afecta la capitalización de mercado, pero rara vez se contabiliza como "planta y equipo" y no tiene relación con el tamaño de la fuerza 
de trabajo de las compañías, nuestra comparación es intrínsecamente sesgada. No demuestra una distorsión sino una simple mala medición.

Y quizá haya aquí una mala medición, pero, ¿cómo podemos estar seguros? Noten que los economistas conocen aquí la "magnitud" de la tecnología no observándola de manera directa (lo que nadie puede realmente) sino indirecta, a través de su reflejo en el espejo: la deducen como el residuo entre la capitalización de mercado y el valor en dólares de la planta y el equipo.

La mayoría de los economistas encuentran el "residuo" tecnológico en su estudio de las funciones de producción. Estas funciones pretenden explicar el nivel de producto mediante el nivel de insumos productivos; y son muy malas para explicarlo. Usualmente, dejan sin explicar una gran variación del producto -el infame "residuo"- cuya existencia los economistas suelen atribuir a su incapacidad para cuantificar el "conocimiento" (llamándolo una "medida de nuestra ignorancia").

Esta incapacidad tiene consecuencias devastadoras. Como ilustración consideremos dos funciones de producción hipotéticas, con insumos físicos aumentados por la tecnología: 1) $Q=2 N+3 L+5 \mathrm{~K}+$ $T$ y 2) $Q=4 N+2 L+10 K+T$, donde $Q$ denota el producto, $N$ el trabajo, $L$ la tierra, $K$ el capital y $T$ la tecnología. Ahora, supongamos que $Q$ es 100, $N$ es 10, $L$ es 5 y $K$ es 4 . Así, $T$ debe ser 45 en la función 1) y 10 en la función 2). Pero como la tecnología no se puede medir, no podemos saber cuál función de producción es correcta, de modo que ambas $-y$, por extensión, toda función aumentada por la tecnologíapueden reclamar validez incontrovertible. Pero si la producción no se puede describir objetivamente, ¿qué queda de la función de oferta, del equilibrio y de todo el edificio llamado economía?

El residuo de la función de producción está relacionado pero es diferente del residuo entre la capitalización y la cantidad de capital real: el primero supuestamente mide la contribución de la tecnología al producto, mientras que el segundo supuestamente cuantifica la magnitud real de la tecnología. Pero ambos residuos comparten la propiedad de ser convenientemente invisibles y por tanto irrefutables.

¿Qué ocurre si el espejo de la capitalización miente y el "residuo" nos da una lectura falsa? Por ejemplo, ¿si General Motors fuera la que posee la tecnología "más grande" y el mercado de activos simplemente "fijara un mal precio" a las dos acciones para sugerir erróneamente lo contrario? Y luego existe la posibilidad de que 2005 no haya sido un año de EPC - lo cual asumimos en gracia de la discusión- y que por ello nuestras medidas (nominales) de la cantidad de capital real de 
las dos compañías están de hecho distorsionadas. ¿Cómo sabemos que el mercado omnisapiente no fijó también un mal precio a estos activos? Y si no hay manera de saberlo, ¿cómo podemos decir algo significativo, y mucho menos definitivo, sobre el presunto "tamaño" de la tecnología?

\section{LA QDE TOBIN: ADICIÓN DE INTANGIBLES}

La gráfica 4 suscita la misma pregunta, aunque a escala mucho mayor. Mientras que nuestra comparación de Microsoft y General Motors se limita a dos firmas en un punto del tiempo, en la gráfica 4 vemos todas las corporaciones de Estados Unidos desde los años treinta hasta el presente. La gráfica presenta dos series. La línea sólida es nuestra (pseudo) referencia real; muestra el costo corriente, o de remplazo, de los activos fijos corporativos (es decir, lo que costaría producirlos, cada año, a los precios prevalecientes y no a precios históricos). La línea punteada es la magnitud correspondiente de las finanzas. Mide

\section{Gráfica 4}

La "cantidad" de capital en Estados Unidos

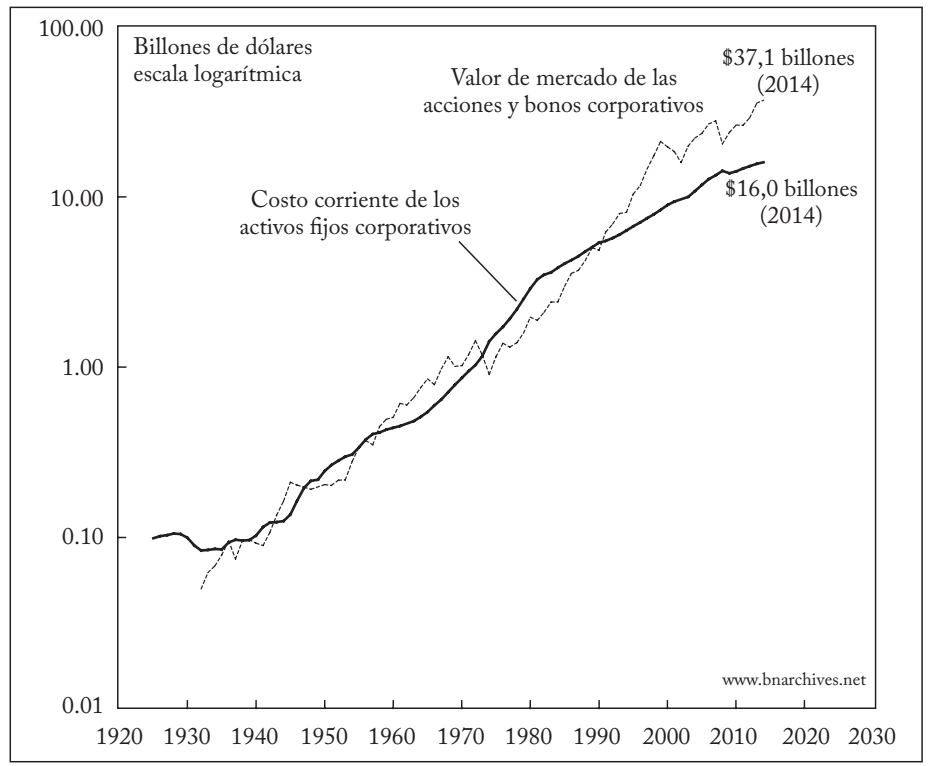

Nota: el valor de mercado de las acciones y bonos es neto de tenencias extranjeras de residentes en Estados Unidos. Fuente: U.S. Bureau of Economic Analysis a través de Global Insight (código de serie: FAPNREZ para el costo corriente de los activos fijos corporativos). El valor de mercado de las acciones y bonos empalma series de las dos fuentes siguientes. 1932-1951: Global Financial Data (valor de mercado de las acciones corporativas y valor de mercado de los bonos en la Bolsa de Valores de Nueva York). 1952-2014: Junta de la Reserva Federal a través del Global Insight (códigos de serie: FL893064105 para el valor de mercado de las acciones corporativas, FL263164103 para el valor de mercado de acciones extranjeras mantenidas por residentes en Estados Unidos, incluyendo ADR, FL893163005 para el valor de mercado de bonos corporativos y extranjeros, y FL263063005 para el valor de mercado de bonos extranjeros mantenidos por residentes en Estados Unidos). 
la capitalización total de las acciones y bonos corporativos, un agregado que constituye una reclamación sobre la suma total de los activos reales subyacentes y que presumiblemente la refleja.

Como dibujamos las dos series en escala logarítmica, las discrepancias entre ellas pueden ser muy grandes aunque se vean pequeñas en la gráfica. Esas discrepancias se calibran en la gráfica 5, que muestra el índice $Q$ de Tobin, en nombre de James Tobin. Para nuestro propósito, la Q de Tobin es una medida amplia del desajuste financieroreal. Calcula, para cada año, la proporción entre el valor de mercado de las corporaciones (en el numerador) y el costo de remplazo de su planta y su equipo (en el denominador). Si las finanzas se ajustan a la realidad, las dos magnitudes son iguales y la Q de Tobin será igual a 1 . Si hay un desajuste, la Qde Tobin será mayor o menor que 1.

La gráfica 5 tiene dos características notables. Primera, muestra que el valor histórico medio de la $\mathrm{Q}$ de Tobin no es 1 , sino ligeramente superior a 1,2. Segunda, muestra marcadas variaciones de $Q_{2}$ que van de un punto bajo de 0,6 a uno alto de 2,5. Estas variaciones no son aleatorias, sino más bien cíclicas y persistentes. Examinemos estas dos características más de cerca.

Gráfica 5

La Q de Tobin en Estados Unidos

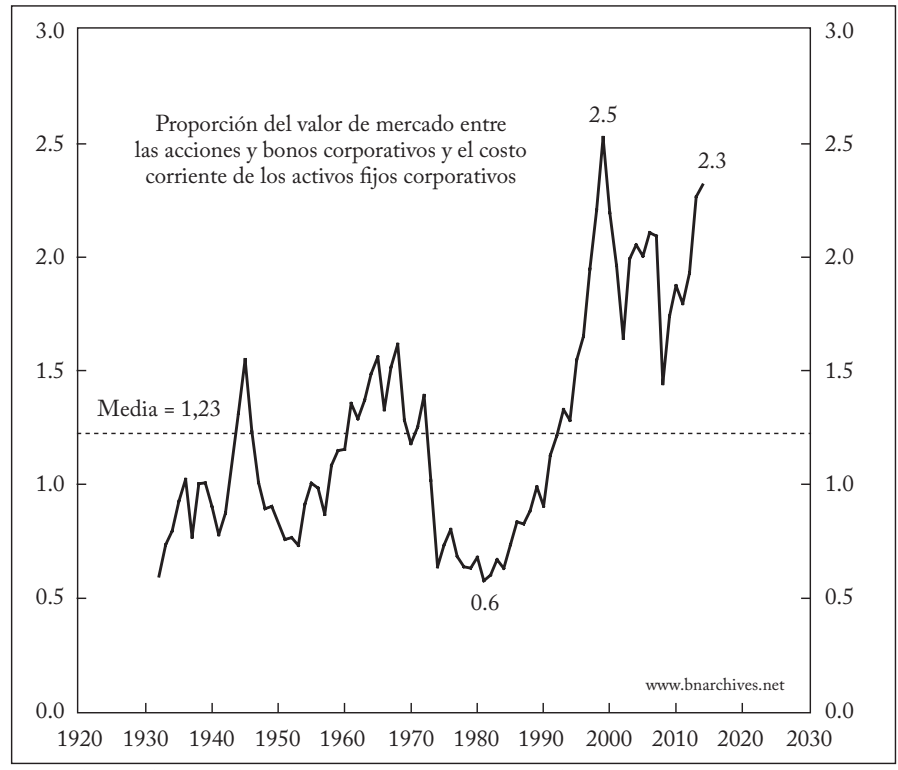

Nota: el valor de mercado de las acciones y bonos es neto de tenencias extranjeras mantenidas por residentes en Estados Unidos. El último dato es de 2014 (basado en el valor medido de las acciones y bonos corporativos y el costo corriente estimado de los activos fijos corporativos)

Fuente: ver la gráfica 4. 
¿Por qué el promedio histórico de la Q de Tobin es mayor que 1? La respuesta convencional, igual que en el caso de Microsoft-General Motors, es una mala medición. Cuando los físicos eran incapaces de cuadrar sus cálculos acerca de la estructura y la expansión del universo, no se lanzaron a cambiar su teoría; en vez de ello, resolvieron el problema, al menos provisionalmente, usando como hipótesis la existencia de materia "oscura" invisible, cuya masa supuesta, cuando se añadía a la masa de materia observada, hacía coherentes sus cálculos. Los economistas hacen esa misma cosa con el desajuste real-financiero. La razón para que esa capitalización tienda a ser mayor que el "capital real" -dicen- es que los activos fijos son solo una parte de la imagen. La otra parte está formada por activos intangibles igualmente productivos. Infortunadamente, la mayoría de esos intangibles, como la materia oscura de los físicos, son invisibles. Y esta invisibilidad explica por qué las finanzas a menudo se desajustan de la realidad y por qué la $Q$ de Tobin es en promedio mayor que 1.

Muchos economistas arguyen que los intangibles se han vuelto más importantes desde el inicio de la "revolución de la información"y de la "economía del conocimiento" en los años ochenta; exactamente cuando la Q de Tobin empezó a aumentar. Según esa visión, las corporaciones han acumulado cada vez más activos invisibles en forma de mejor tecnología, mejor organización, alta tecnología, sinergia y otras bendiciones relacionadas con el conocimiento. Estos intangibles a su vez han aumentado la cantidad de capital y han llevado, por tanto, a una mayor capitalización. Pero los contadores siguen siendo conservadores, y la mayoría de los intangibles no se registran como activos fijos en el balance. Y como el numerador capitalizado de la Q de Tobin tiene en cuenta estos intangibles mientras que el denominador de los activos fijos usualmente no, terminamos con un desajuste creciente. A mediados de la década de 2000, algunos cálculos conjeturales sugerían que los intangibles representaban el $80 \%$ del total de activos corporativos; frente a menos del $20 \%$ treinta años antes.

Aunque populares, estas afirmaciones son muy dudosas. Igual que en el caso Microsoft-General Motors, aquí también el capital intangible se calcula como un residuo, restando el valor de los activos fijos de la capitalización de mercado. Si aceptamos ese método-como lo acepta la mayoría de los economistas- también debemos aceptar que el capital intangible es una criatura sumamente flexible, capaz de ampliarse rápidamente (como en los años ochenta y noventa, cuando la Q de Tobin se elevó en un mercado en alza) y de contraerse rápidamente (como lo hizo durante el mercado a la baja de la década 
de 2000, cuando la Q de Tobin se derrumbó). ¿Pero esta flexibilidad tiene sentido?

Dado que el conocimiento técnico tiende a cambiar muy gradualmente y rara vez se contrae, ¿cómo podría su "magnitud" saltar varias veces en una breve década, y caer precipitadamente en la siguiente? $\mathrm{Y}$ eso no es todo. Aceptar aquí el método del residuo es admitir que el capital intangible se puede volver negativo; porque de otro modo, ¿Cómo podríamos explicar que la Q de Tobin haya caído por debajo de 1 ?

\section{AUGE Y CAÍDA: IRRACIONALIDAD}

¿Qué hacen los economistas para evitar estas inverosimilitudes? Añaden la irracionalidad. Los libros de texto presentan agentes económicos racionales y mercados eficientes; pero cuando se los pone contra la pared, incluso los fundamentalistas admiten que la realidad es rara vez tan prístina. En la práctica, los agentes económicos son presa de emociones, a menudo están mal informados y a veces son delirantes. Además, y lamentablemente, el "mercado", que en los libros de texto se describe perfecto, es contaminado y distorsionado fuertemente por funcionarios y autoridades públicas, oligopolios y gente con información privilegiada, sindicatos y ONG (y, más recientemente, por un cúmulo de actores no económicos, desde sectas religiosas hasta organizaciones terroristas). Este coctel tóxico significa que, a diferencia de la teoría, los resultados reales del mercado pueden ser irracionales y a veces impredecibles.

Los mercados irracionales e impredecibles tienen sus desventajas. Hicieron que Isaac Newton perdiera una fortuna cuando estalló la Burbuja del Mar del Sur en el siglo XVIII y que Irving Fisher perdiera una suma mucho mayor $-\$ 100$ millones a precios de hoy- cuando se desplomó la Bolsa de Valores de Estados Unidos en 1929. Humillado, Newton observó que "podía calcular el movimiento de las estrellas, pero no la locura de los hombres". Fisher, en cambio, siguió siendo optimista. En vez de alzar las manos con desespero, pasó a fundar la Comisión Cowles, Econometrica y otras iniciativas, todas con la esperanza de dar al arte de ganar dinero un fundamento verdaderamente científico.

Que estas iniciativas hayan facilitado la ganancia de dinero sigue siendo una pregunta abierta, pero aliviaron el dominio de la economía neoclásica estrictamente "racional" en asuntos financieros. Hoy se dice que la capitalización de mercado no consiste en dos componentes sino en tres: activos tangibles, activos intangibles y el pesimismo u 
optimismo “irracional” de los inversionistas. Y muchos ahora creen que este último componente explica por qué la $Q$ de Tobin es tan volátil.

¿Cómo se manifiesta esta volatilidad? Un analista financiero típico podría describir el proceso de la siguiente manera. En los buenos tiempos -es decir, cuando la acumulación real es alta y creciente- los inversionistas se vuelven excesivamente optimistas. Su exuberancia les hace apostar al alza de precios de los activos financieros por encima del valor "verdadero" del capital real subyacente. Esa reacción excesiva puede servir para explicar, por ejemplo, el boom asiático de mediados de los noventa, el boom de las empresas de alta tecnología de finales de los noventa y el boom de las subprime de mediados de la década pasada. En este escenario, el capital real se eleva, pero el capital financiero, impulsado por el optimismo exagerado, se eleva aún más rápidamente.

\section{Gráfica 6}

El mundo según las escrituras

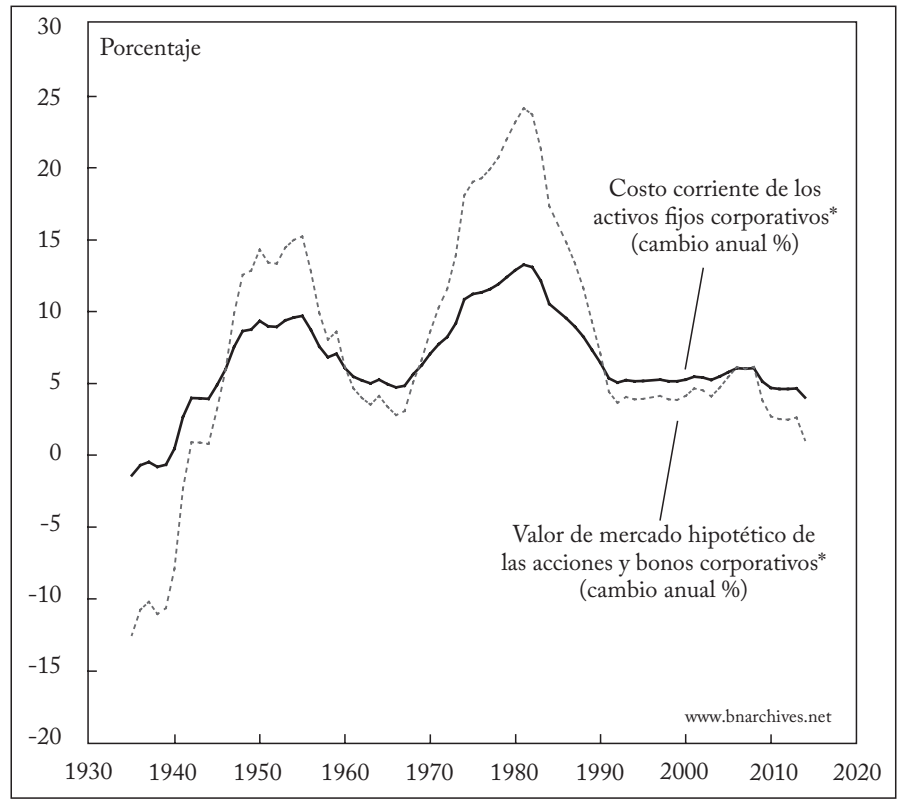

* Calculado anualmente sumando al promedio histórico de la tasa de crecimiento de los activos fijos corporativos corrientes 2,5 veces la desviación de la tasa anual de crecimiento con respecto a su promedio histórico.

Nota: la serie se suavizó usando promedios móviles de 10 años. Los últimos datos son de 2013.

Fuente: U.S. Bureau of Economic Analysis a través de Global Insight (código de serie: FAPNREZ para el costo corriente de los activos fijos corporativos).

Se dice que ese mismo patrón, aunque en reversa, se sigue en el descenso. La desaceleración de la acumulación real hace que los inversionistas se vuelvan excesivamente pesimistas, y ese pesimismo 
los lleva a empujar hacia abajo el valor de los activos financieros más rápidamente que el descenso de la acumulación real. En vez de excedernos ahora somos cautelosos. Y esa cautela -continúa el argumento- puede explicar por qué, durante la Gran Depresión, cuando los activos fijos se contrajeron en solo un 20\%, la Bolsa de Valores cayó un $70 \%$, y por qué, a finales de la década pasada, la Bolsa de Valores cayó en más del 50\% mientras que la acumulación de activos fijos simplemente se desaceleró.

Este patrón de irracionalidad se ilustra en la gráfica 6. La línea sólida mide la tasa real de cambio de los activos al precio de costo de remplazo, suavizada usando un promedio móvil de 10 años ${ }^{10}$. A diferencia de la línea gruesa, la línea punteada es hipotética. Simula cómo serían las alzas y bajas de la capitalización si los inversionistas fueran excesivamente optimistas en la fase ascendente y excesivamente pesimistas en la fase descendente (el cálculo exacto de la serie se explica en las notas anexas a la gráfica).

Tales simulaciones ayudan a los analistas de mercado a urdir orden a partir del caos. Demuestran que la irracionalidad de los inversionistas -aunque embarazosa, lamentable e inconveniente- es limitada y, por tanto, manejable y predecible. La acrecencia del optimismo excesivo de los inversionistas durante el alza se revierte durante el descenso, cuando esos mismos inversionistas se vuelven excesivamente pesimistas. La euforia impulsada por el alza que da lugar a una burbuja de "riqueza falsa" y a un aumento de la $Q$ de Tobin es eventualmente sustituida por el temor, lo que hace que la riqueza parezca más pequeña que lo que es realmente y que la $\mathrm{Q}$ de Tobin se desplome.

\section{UN CASTILLO DE NAIPES}

Ahora todo encaja finalmente en su sitio. 1) El "capital real" no se puede medir y probablemente no tiene una cantidad única, pero eso está bien si podemos pretender que su magnitud es proporcional al precio corriente de los activos fijos. 2) Los promedios de la Q de Tobin son mayores que 1 ; pero eso también está bien, puesto que el valor más grande se puede atribuir a la existencia de activos intangibles muy productivos que, infortunadamente, nadie puede ver realmente. Y 3) la Q de Tobin fluctúa fuertemente, lo que se puede admitir porque el mercado de activos es imperfecto y los humanos no son siempre racionales; pero eso también está bien, porque las oscilaciones de

10 Esta serie excluye los intangibles, pero puesto que aquí no presentamos niveles sino tasas de cambio, podemos asumir convenientemente que la suma de activos tangibles e intangibles seguiría un patrón de crecimiento similar al de los activos tangibles. 
mercado de activos están limitadas en forma segura y bastante predecible y, más importante, se mueven junto con la acumulación "real".

¿O no?

Nótese que la serie de capitalización de la gráfica 6 es totalmente imaginaria. Tal como es, no refleja la realidad del mercado sino los supuestos de la teoría; en particular, el supuesto de que la tasa de crecimiento de la capitalización amplifica la del capital real, aunque se mueve junto con ella. ¿Pero es este un supuesto correcto?

De acuerdo con la gráfica 7 , la respuesta es un no rotundo.

Gráfica 7

Acumulación de capital en Estados Unidos: ficción versus realidad

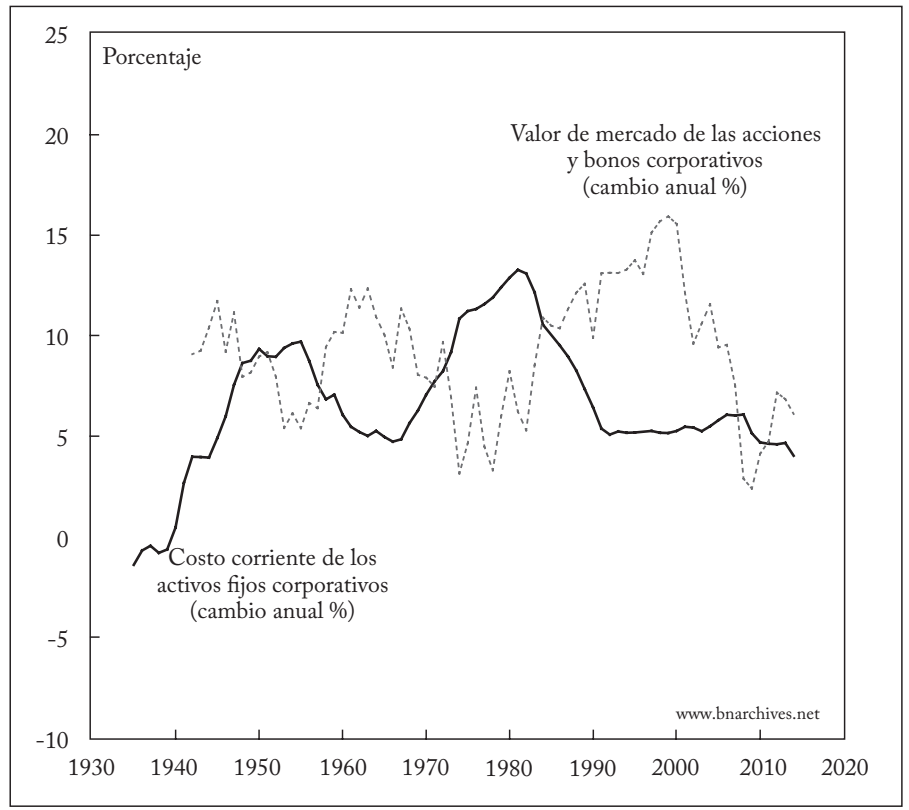

Nota: el valor de mercado de las acciones y bonos es neto de tenencias extranjeros de residentes en Estados Unidos. La serie se presenta como promedio móvil de 10 años. Los últimos datos son de 2014 para el valor de mercado de las acciones y bonos corporativos y de 2013 para el costo corriente de los activos fijos corporativos.

Fuente: ver la gráfica 4.

Aquí la línea sólida es igual a la de la gráfica 6. Mide la tasa de cambio del costo de remplazo de los activos fijos. La línea punteada, sin embargo, ya no es hipotética: mide la tasa real de cambio del valor de las acciones y bonos corporativos. Y es aquí donde la dualidad real/ nominal y la tesis asociada del desajuste topan con un muro de ladri1lo. A diferencia de la gráfica 6, donde las alzas y bajas de la serie de capitalización amplifican las de los activos fijos, aquí parecen moverse exactamente en la dirección opuesta. 
Estas no son fluctuaciones de corto plazo. La historia del proceso muestra un patrón de ola de muy largo plazo, con una duración cíclica de 15 a 40 años. Además el movimiento contracíclico de las dos series parece ser muy sistemático.

Ahora bien, a diferencia de los resultados que presentamos más atrás, que aceptamos pasar por alto en aras del argumento, el patrón inverso evidente en la gráfica 7 es patentemente inconsistente con la dualidad fundamental entre capital real y capital financiero. Quizá podamos aceptar que el capital real no tiene un quántum material, y luego pretender que este quántum es proporcional al precio de mercado de los bienes de capital subyacentes. Quizá podamos aceptar que hay activos invisibles que nadie puede observar, y sin embargo creer que el mercado de activos omnisapiente puede medirlos indirectamente por nosotros, como un residuo. Y quizá podamos admitir que los agentes económicos son irracionales, y luego suponer que su fijación imperfecta de precios de los activos es no obstante limitada, y que oscila alrededor del precio "verdadero" del capital real. Pero supera toda credulidad observar que la acumulación de activos reales y financieros se mueve en direcciones opuestas, y sin embargo sostener que este último movimiento se deriva del primero y lo refleja.

A los capitalistas de hoy en día -o inversionistas, como ahora se los conoce-no les importa el "capital real". Son indiferentes a los medios de producción, el trabajo y el conocimiento. No pierden el sueño por la racionalidad individual y la eficiencia del mercado. Y pueden vivir con mercados libres e "intervención del gobierno". Lo único que les importa es su capitalización financiera. Este es su "Moisés y los profetas". E1 resto es solo un medio para un fin.

La promesa de la economía política clásica, y después de la economía, era explicar y justificar el dominio del capital: mostrar que los capitalistas, mientras persiguen sus intereses pecuniarios, impulsan al resto de la sociedad hacia adelante. La acumulación de valores de capital-explicaban los economistas-va de la mano con el amasamiento de medios "reales" de producción y, por tanto, con el crecimiento de la producción, el empleo, el conocimiento, la racionalidad, la eficiencia y el laissez faire. Pero, entonces, si el caso de Estados Unidos es representativo y las tasas de crecimiento de la capitalización y del "capital real" no se mueven juntas sino a la inversa, los intereses de los dirigentes capitalistas se contraponen a los de la sociedad. Y si ese es de hecho el caso, ¿cuál es el uso de la economía? 


\section{FIN DEL JUEGO}

Cuando el capital surgió en los burgos europeos de finales de la Edad Media, parecía un inicio muy prometedor: contrarrestó el estancamiento y la violencia del ancien régime con la promesa de dinamismo, ilustración y prosperidad, y remplazó la brujería teológica de la Iglesia con una lógica abierta, transparente y fácil de entender. Pero una vez el capital tomó el control de las palancas de la sociedad, esa marcada diferencia se empezó a desdibujar. El funcionamiento interno del capital se hizo cada vez más opaco: parecía difícil descifrar sus alzas y bajas, sus crisis parecían misteriosas, amenazadoras y difíciles de manejar, y su verdadera naturaleza y su definición se hicieron más elusivas y más difíciles de entender.

La economía política - la primera ciencia de la sociedad-intentó describir el nuevo orden del capital. En este sentido, era la ciencia del capital. El dominio del capital surgió y se consolidó junto con la ciencia moderna, y los métodos de la economía política se desarrollaron de la mano con los de la física, la química, las matemáticas y la estadística. En el siglo XVII, la revolución científica, junto con los procesos de urbanización, el paso de la producción agrícola a la manufacturera y el desarrollo de nuevas tecnologías, dio lugar a una visión mecánica del mundo, a una nueva cosmología secular cuyos arquitectos intelectuales promovieron como precursora de la libertad y el progreso. Y fue esta nueva cosmología mecánica -en sí misma una consecuencia parcial del capitalismo- la que los economistas políticos trataron de adaptar al capital.

Sus intentos de casar la lógica de la acumulación con las leyes mecanizadas del cosmos están impresos en toda la economía política clásica y en las ciencias sociales que luego dio a luz, y son particularmente evidentes en las diversas teorías del capital. El razonamiento cuantitativo y las ecuaciones compactas, el cálculo newtoniano y las fuerzas, la conservación de la materia y la energía, la imposición de la probabilidad y la estadística sobre la incertidumbre: estos y otros métodos similares han sido incorporados, metafórica o directamente, en el estudio del capitalismo y la acumulación.

Pero como hemos visto en este artículo, en el siglo pasado ese matrimonio fracasó. Las modernas disciplinas de la economía y las finanzas están inundadas de modelos muy complicados, repletas de los métodos estadísticos más actualizados, de programas de computador y de montones de datos; aunque su capacidad para explicar el mundo del capital es muy limitada en el mejor de los casos, y más todavía para justificarlo. Sus categorías básicas suelen ser lógicamente defectuosas 
y empíricamente inutilizables, e incluso después de ser remendadas masivamente con supuestos ad hoc e inversiones circulares, aún siguen generando enormes "residuos" y "medidas de ignorancia" inobservables.

En este sentido, la humanidad hoy se encuentra en una situación no muy diferente de la que prevalecía en Europa en el siglo XVI, cuando el feudalismo finalmente dio paso al capitalismo y el mundo cerrado y geocéntrico de la Iglesia estaba a punto de sucumbir ante el universo secular y abierto de la ciencia. La doctrina actual del capitalismo, cada vez más desintonizada de la realidad, hoy se arriesga a un destino similar al de su predecesora feudal cristiana. Los retos globales crecientes - de la sobrepoblación y la destrucción ambiental, pasando por el cambio climático directo y el pico de la energía, hasta la pérdida de autonomía y el riesgo de desintegración social- no pueden ser manejados por una pseudo ciencia que no puede definir sus principales categorías y cuya principal herramienta explicativa son las "distorsiones". No se puede construir toda una cosmología social basada en los supuestos de racionalidad individual, equilibrio y mercados perfectos; y luego acusar a la irracionalidad, el desequilibrio y las imperfecciones por los fracasos de esta cosmología. En la ciencia, estas excusas y estas culpas equivalen a una auto refutación.

Lo que hoy necesitamos no son mejores herramientas, modelos más precisos y datos mejores, sino una manera de pensar diferente, una cosmología totalmente nueva para la era post-capitalista.

\section{REFERENCIAS BIBLIOGRÁFICAS}

1. Fisher, I. The rate of interest, Nueva York, Macmillan, 1907.

2. Marx, K. Capital. A critique of political economy. vol. 3, "The process of capitalist production as a whole", F. Engels, ed., Nueva York, International Publishers, 1894.

3. Nitzan, J. y S. Bichler. Capital as power: A study of order and creorder, Londres y Nueva York, Routledge, 2009, [http://bnarchives.yorku. $\mathrm{ca} / 259 /]$.

4. Perelman, M. "The phenomenology of constant capital and fictitious capital", Review of Radical Political Economics 22, 2-3, 1990. 